\title{
The Growing Promiscuity of G Protein Coupled Receptors
}

\section{Peter J Little*, Micah L Burch and Narin Osman}

Discipline of Pharmacy, School of Medical Sciences and Diabetes Complications Group, Metabolism, Exercise and Disease Program, Health Innovations Research Institute, RMIT University, Melbourne, Victoria 3083 Australia

Cell surface receptors are the major pathways for the transmission of information from outside to inside cells. The major classes of receptors are the enzymatically active protein tyrosine kinase and protein serine/threonine kinases and the non-enzymatically active Seven Transmembrane G Protein Coupled Receptors (GPCR). GPCRs are the largest class of receptors and provide the greatest number of targets for therapeutic agents with drugs such as Angiotensin Receptor Blockers (ARBs) being amongst the most efficacious and relatively safe drugs in cardiovascular medicine.

Receptors utilise signalling pathways which most usually result in altered gene transcription and modifications of cellular phenotype and function. These signalling pathways can intersect and interact within the cell to enhance or negate the relevant responses in a phenomenon known as "cross talk" [1]. However, the interactions can also be at the level that one receptor interacts with another receptor in a phenomenon known as (receptor) transactivation [2]. GPCRs have linear signalling pathways involving the propagation of signals via second messengers such as phospholipase C, adenylcyclase and phosphoinositide-3kinase, but two decades ago it was additionally discovered that cognate ligand activation of a GPCR could also lead to transactivation of Protein Tyrosine Kinase Receptors (PTKRs) [3]. A specific example involves the transactivation of the Epidermal Growth Factor Receptor (EGFR) by the GPCR agonist's thrombin, Lysophosphatidic Acid (LPA) and Endothelin-1 (ET-1) in Rat-1 fibroblasts [3]. Linear GPRC signalling produces relatively rapid responses (sec or $\mathrm{min}$ ); an example would be the angiotensin II interaction with its receptor leading to activation of phospholipase $\mathrm{C}$ and the generation of inositol 1,4,5-trisphosphate and the release of calcium ions from the endoplasmic reticulum leading to the contraction of a blood vessel [4]. Angiotensin II or thrombin signalling via this linear pathway in cells in the Go stage of the cell cycle is not usually sufficient to produce a mitogenic response [5]. However, thrombin can also activate its receptor leading to transactivation of a PTKR such as the EGFR and this leads to the generation of the mitogenic precursor of phosphorylated p38 which follows its cascade to produce a full mitogenic response in vascular smooth muscle cells [6]. Studies over the last two decades have revealed that the major two pathways through which this transactivation occurs are ligand dependent and ligand independent. Ligand dependent transactivation, as its name suggests, involves the cleavage and liberation of a PTKR ligand, typically via a cell surface Matrix-Metalloproteinases (MMPs), that then follows on to activate the PTKR in an autocrine/paracrine manner. The most well characterised example of this includes the activation of MMPs, leading to the liberation of Heparin BindingEGF and subsequent ligand mediated receptor activation [7]. As this mechanism passes through the membrane three times before receptor activation, it is also referred to as 'triple membrane passing' transactivation. The second mode of GPCR mediated transactivation is devoid of ligand involvement, instead, the GPCR activates intracellular kinases such as Src, which directly phosphorylate the intracellular autophosphorylation sites of the PTKR, leading to activation [8]. Receptor transactivation greatly expands the repertoire of cellular responses associated with activation of the GPCR. Until recently this phenomenon of GPCR receptor transactivation has been restricted to members of the protein tyrosine kinase family including receptors for EGF, PDGF, IGF-1 and FGF [3,9-11]. However, there have now been several reports, including from our own laboratory, that GPRCs can transactivate members of the protein serine/threonine kinase receptor family, specifically those of the Transforming Growth Factor (TGF) $-\beta$ superfamily. In this case the interaction of a cell with a GPCR agonist results in the slightly delayed production of phosphorylated Smad transcription factors (namely, phosphoSmad2) which are the immediate downstream products resulting from the activation of the Type I TGF- $\beta$ receptor (T $\beta$ RI) which possess serine/threonine kinase activity and is known also as Activin-like kinase 5 (Alk5) (12-15). The reported examples of this phenomena are the transactivation of Alk5 by thrombin and ET-1 in human vascular smooth muscle cells $[12,13]$, and by thrombin and LPA in mouse lung epithelial cells $[14,15]$, as well as the transactivation of the BMP receptor (part of the TGF- $\beta$ superfamily) by serotonin in porcine and human aortic smooth muscle cells. The phenomenon has been described in detail to implicate the involvement of both the GPCR and Alk5. Mechanistically, data shows that the transactivation involves the small GTP binding protein RhoA and hence ROCK, the cytoskeleton and cell surface integrin $[14,15]$. Based on this data our current speculation is that the GPCR ligand interacts with the cognate GPCR to activate RhoA/ROCK, modifying the cytoskeleton which in turn mechanically perturbs the cell membrane leading to the opening of the Large Latent Complex (LLC) [16]. The LLC which is embedded in the extracellular matrix, encases the TGF- $\beta$ ligand; this leads to the 'presentation' of the TGF- $\beta$ as the cognate ligand (still within the LLC) to Alk5 and hence allowing for Alk5-mediated serine/threonine phosphorylation of the regulatory Smad transcription factors [17]. Perhaps due to this mechanism and restricted site specific interaction between the active TGF- $\beta$ in the LLC and its receptors, the transactivation response (increase in phosphoSmad2) has so far been seen to be of lower magnitude compared to the response arising from the introduction of exogenous free active TGF- $\beta$. The transactivation response is functionally active as evidenced in two ways. Firstly, the phosphoSmad2 generated by this pathway in human vascular smooth muscle cells translocates and can be identified in the cell nucleus. Secondly, phosphoSmad2 produces functional responses such as the stimulation of proteoglycan synthesis $[12,13]$. In our own work we have demonstrated that this thrombin receptor GPCR (Protease Activated Receptor 1) to Alk5transactivation pathway leads to the stimulation of the synthesis of the core protein for the small leucine rich lipid binding proteoglycan, biglycan as well as activation of the Golgi apparatus and the synthesis of hyperelongated

*Corresponding author: Peter J Little, Discipline of Pharmacy, School of Medical Sciences and Diabetes Complications Group, Health Innovations Research Institute, RMIT University, Melbourne, Victoria 3083 Australia; Tel: 61-3-99256686; E-mail: peter.little@rmit.edu.au

Received October 19, 2012; Accepted October 21, 2012; Published October 25, 2012

Citation: Little PJ, Burch ML, Osman N (2012) The Growing Promiscuity of G Protein Coupled Receptors. Clin Exp Pharmacol 2:e110. doi:10.4172/2161$1459.1000 \mathrm{e} 110$

Copyright: (c) 2012 Little PJ, et al. This is an open-access article distributed under the terms of the Creative Commons Attribution License, which permits unrestricted use, distribution, and reproduction in any medium, provided the original author and source are credited. 
glycosaminoglycan (GAG) chains on the biglycan [12]. Others have shown that in mouse lung epithelial cells, the transactivation of Alk5 by thrombin and LPA is an important event in lung injury. Specifically, interference of this pathway significantly protects mice from bleomycin induced lung injury and oedema $[14,15]$.

GPCRs are thus especially promiscuous in their ability to transactivate at least some members of both of the major kinase families of cell surface receptors, these being protein tyrosine kinase and protein serine/threonine kinase receptors. This is not a question of "everything activates everything" because at least in the situation of one major pathway of GPCR transactivation of Alk5, the pathway that would represent reverse transactivation being the generation of $\mathrm{IP}_{3}$, TGF- $\beta$ does not transactivate the thrombin GPCR, PAR- 1 as no increase at all in $\mathrm{IP}_{3}$ is observed when cells are treated with TGF- $\beta$ [12]. The full implication of this extension to the paradigm of GPCR transactivation signalling is not yet clear. Undoubtedly, the extent of physiological and potentially pathological responses to GPCRs is increased - whether or not this makes it easier or more difficult to address therapeutically is the major question. There is a need to identify the exact involvement of GPCRs, protein tyrosine kinase and protein serine/threonine kinases in each pathological condition and then to determine if a point of therapeutic intervention can be identified. Clearly, more work is required to identify the full range of partners involved in GPCR to protein serine/threonine kinase transactivation and also the mechanism(s) of these transactivation pathways.

\section{Acknowledgements}

Finally, no Editorial in relation to GPCRs would be complete without acknowledging the recent award of a Novel prize in Chemistry to the two Americans, Robert J Lefkowitz and Brian K Kobilka.

\section{References}

1. Guo X, Wang X F (2009) Signaling cross-talk between TGF-beta/BMP and other pathways. Cell Res 19: 71-88.

2. Little PJ, Burch ML, Al-Aryahi S, Zheng W (2011) The paradigm of g protein receptor transactivation: a mechanistic definition and novel example. Scientific World Journal 11: 709-714.

3. Daub H, Weiss FU, Wallasch C, Ullrich A (1996) Role of transactivation of the EGF receptor in signalling by G-protein-coupled receptors. Nature 379: 557 560

4. Griendling KK, Tsuda T, Berk BC, Alexander RW (1989) Angiotensin II stimulation of vascular smooth muscle. J Cardiovasc Pharmacol 6: S27-S33.
5. Cramer EM, Masse JM, Caen JP, Garcia I, Breton-Gorius J, et al. (1993) Effect of thrombin on maturing human megakaryocytes. Am J Pathol 143: 1498-1508.

6. Kanda $Y$, Mizuno K, Kuroki Y, Watanabe $Y$ (2001) Thrombin-induced p38 mitogen-activated protein kinase activation is mediated by epidermal growth factor receptor transactivation pathway. $\mathrm{Br} \mathrm{J}$ Pharmacol 132: 1657-1664.

7. Prenzel N, Zwick E, Daub H, Leserer M, Abraham R, et al.(1999) EGF recepto transactivation by G-protein-coupled receptors requires metalloproteinase cleavage of proHB-EGF. Nature 402: 884-888

8. Slomiany BL, Slomiany A (2004) Src-kinase-dependent epidermal growth factor receptor transactivation in salivary mucin secretion in response to betaadrenergic G-protein-coupled receptor activation. Inflammopharmacology 12 : 233-245

9. Heeneman S, Haendeler J, Saito Y, Ishida M, Berk BC (2000) Angiotensin II induces transactivation of two different populations of the platelet-derived growth factor beta receptor. Key role for the p66 adaptor protein. Shc J Bio Chem 275: 15926-15932.

10. Rao GN, Delafontaine P, Runge MS (1995) Thrombin stimulates phosphorylation of insulin-like growth factor-1 receptor, insulin recepto substrate-1, and phospholipase C-gamma 1 in rat aortic smooth muscle cells. J Biol Chem 270: 27871-27875.

11. Belcheva MM, Haas PD, Tan Y, Heaton VM, Coscia CJ (2002) The fibroblast growth factor receptor is at the site of convergence between mu-opioid recepto and growth factor signaling pathways in rat $\mathrm{C} 6$ glioma cells. J Pharmacol Exp Ther 303: 909-918.

12. Burch ML, Ballinger ML, Yang SN, Getachew R, Itman C, et al. (2010) Thrombin stimulation of proteoglycan synthesis in vascular smooth muscle is mediated by protease-activated receptor-1 transactivation of the transforming growth factor beta type I receptor. J Biol Chem 285: 26798-26805.

13. Little PJ, Burch ML, Getache R, Al-aryahi S, Osman N (2010) Endothelin-1 stimulation of proteoglycan synthesis in vascular smooth muscle is mediated by endothelin receptor transactivation of the transforming growth factor-[beta] type I receptor. J Cardiovasc Pharmacol 56: 360-368.

14. Jenkins RG, Su X, Su G, Scotton CJ, Camerer E, et al. (2006) Ligation of protease-activated receptor 1 enhances alpha(v)beta6 integrin-dependent TGF-beta activation and promotes acute lung injury. J Clin Invest 116: 16061614.

15. Xu MY, Porte J, Knox AJ, Weinreb PH, Maher TM, et al. (2009) Lysophosphatidic acid induces alphavbeta 6 integrin-mediated TGF-beta activation via the LPA2 receptor and the small G protein G alpha(q). Am J Pathol 174: 1264-1279.

16. Liu Y, Ren W, Warburton R, Toksoz D, Fanburg B L (2009) Serotonin induces Rho/ROCK-dependent activation of Smads $1 / 5 / 8$ in pulmonary artery smooth muscle cells. FASEB J 23: 2299-2306.

17. Munger JS, Huang X, Kawakatsu H, Griffiths M J, Dalton SL, et al. (1999) The integrin alpha $v$ beta 6 binds and activates latent TGF beta 1: a mechanism for regulating pulmonary inflammation and fibrosis. Cell 96: 319-328. 